\title{
Migration of the femoral component and clinical outcomes after total knee replacement: a narrative review
}

\author{
R. Zinno ${ }^{1}$ S. Di Paolo ${ }^{1}$ (1) G. Ambrosino ${ }^{2} \cdot$ D. Alesi ${ }^{2} \cdot$ S. Zaffagnini ${ }^{1,2} \cdot$ G. Barone $^{3} \cdot$ L. Bragonzoni $^{3}$
}

Received: 6 November 2020 / Accepted: 1 December 2020 / Published online: 14 December 2020

(c) The Author(s) 2020

\begin{abstract}
Loosening is considered as a main cause of implant failure in total knee replacement (TKR). Among the predictive signs of loosening, migration is the most investigated quantitative parameter. Several studies focused on the migration of the tibial component in TKR, while no reviews have been focused on the migration of the femoral component and its influence on patients' clinical outcomes. The aim of this narrative review was (1) to provide information about of the influence of migration in femoral component of TKR prostheses, (2) to assess how migration may affect patient clinical outcomes and (3) to present alternative solution to the standard cobalt-chrome prostheses. A database search was performed on PubMed Central ${ }^{\circledR}$ according to the PRISMA guidelines for studies about Cobalt-Chrome femoral component migration in people that underwent primary TKR published until May 2020. Overall, 18 articles matched the selection criteria and were included in the study. Few studies investigated the femoral component through the migration, and no clear migration causes emerged. The Roentgen Stereophotogrammetric Analysis has been mostly used to assess the migration for prognostic predictions. An annual migration of $0.10 \mathrm{~mm}$ seems compatible with good long-term performance and good clinical and functional outcomes. An alternative solution to cobalt-chrome prostheses is represented by femoral component in PEEK material, although no clinical evaluations have been carried out on humans yet. Further studies are needed to investigate the migration of the femoral component in relation to clinical outcomes and material used.
\end{abstract}

Keywords TKR $\cdot$ Migration $\cdot$ Clinical outcome $\cdot$ RSA $\cdot$ Femoral component $\cdot$ Cobalt-chrome

\section{Introduction}

Total knee replacement (TKR) represents a valid solution for the treatment of end-stage knee osteoarthritis. With the right indications and a reliable and reproducible surgical technique, TKR has an average lifetime of nearly 20 years with in vivo use before revision surgery becomes a necessity [1]. A recent systematic review suggests that the rate of survival at 25 years of TKR is $82 \%$ [2]. Anyway, there is still

S. Di Paolo

stefano.dipaolo@ior.it

1 Dipartimento di Scienze Biomediche e Neuromotorie DIBINEM, Università di Bologna, Via Giulio Cesare Pupilli, 1, 40136, Bologna, BO, Italy

2 Clinica Ortopedica e Traumatologica II, IRCCS Istituto Ortopedico Rizzoli, Via G.B. Pupilli 1, 40136 Bologna, Italy

3 Dipartimento di Scienze per la Qualità della Vita QuVi, Università di Bologna, Bologna, Italy a considerable percentage of TKR failure whose consequent revision surgery might occur earlier than 20-25 years.

There are the causes that can lead to TKR failure: the most frequent is aseptic loosening, followed by infection, unexplained pain, wear, instability, and periprosthetic bone fractures [3-6]. Some of these causes seem to be favored by stress shielding. Indeed, stress shielding is an inevitable phenomenon occurring mainly in the first year after TKR [7]. It is caused by the different stiffness of bone and prosthetic implant, with the latter being nearly one order of magnitude stiffer than the former. It has been demonstrated that stress shielding reduces the load at the bone-prosthesis interface and leads to a gradual bone remodeling and osteolysis which, in turn, can lead to aseptic loosening of the implant or, to a lesser extent, can weaken the bone such that it will fracture [8]. According to Parchi et al. [7] stress shielding causes a constant decrease of periprosthetic bone mineral density (BMD), especially at femoral level, mainly during the first 3-6 months following surgery. 
However, aseptic loosening can also be caused by wear, fixation and/or migration of implant components.

As far as clinical symptoms are concerned, patients presenting with loosening of TKR components and requiring surgery might be completely asymptomatic or present the insidious onset of knee pain, most commonly following a prolonged pain-free interval after the index procedure [9]. Considering the variability in clinical presentation and the need for a prompt diagnosis, migration was deemed a useful predictor for late-term risk for revision of TKR [10]. Indeed, migration has been revealed to be able to predict implant failure, even before clinical symptoms appear. Therefore, migration is advised as a key marker for the quality of a TKR.

Understanding the biological behavior of the bone in contact with the prosthetic surface and how it can affect implant survival and clinical outcomes, might lead to the development of newer designs and materials (e.g., with stiffness closer to the one of the bones) that could provide significant benefits to improve function and survival rate after TKR.

Several studies focused on the migration of the tibial component in TKR, and reviews have already been performed on this topic [10]. No literature reviews have been focused on migration of the femoral component and its influence on patients' clinical outcomes.

Therefore, the purpose of this narrative review was to provide (1) information about the influence of migration in the femoral cobalt-chrome ( $\mathrm{CoCr}$ ) alloy components routinely used in TKR, (2) to assess how this migration may affect patient clinical outcomes, and (3) to present alternative solutions that could replace materials traditionally used in joint prostheses, overcoming the issues related to the mechanical properties.

\section{Material and methods}

\section{Data sources}

An electronic database search was performed on August 1, 2020, using PubMed Central ${ }^{\circledR}$ to identify articles concerning general $\mathrm{CoCr}$ femoral component micromotion in people that underwent primary TKR and how it affected the patients' clinical outcomes.

\section{Search terms}

The terms and keywords used for the literature research were ('femoral') OR ('femur') AND ('micromotion') OR ('migrat*') OR ('sink*') OR ('loss') OR ('loos*') AND ('total knee arthroplasty') OR ('TKA') OR ('total knee replacement') OR ('TKR') located within the title and/or abstract.

\section{Study selection process}

All articles published until August 2020 were included in this review. During the screening procedure, only full-text available items, written in English language, were considered; pre-clinical and 'other animal' studies were included; moreover, reviews were added to the list. Subsequently, the authors further screened title and abstract of the papers, in order to exclude the irrelevant ones for this review. Then, the authors full-screened the remaining papers to leave out those not concerning femoral micromotion analysis, while papers concerning femoral components materials alternative to most used $\mathrm{CoCr}$ were included. In the end, 21 papers were included in the review. Furthermore, 17 papers (gray) mentioned in the selected works were added, since they did not appear in the first screening (Figure 1).

\section{Results}

\section{Causes and evaluation methods of migration}

Only few studies assessing migration of the femoral component were retrieved, in contrast to the numerous studies assessing the migration of the tibial component (Table 1). No clear evidence of migration causes emerged from the analysis. However, a possible cause of migration could be related to bony fixation. Indeed, the lack of bony fixation may cause the implant to become unstable and migrate [1]. Moreover, factors such as low mineral density, bone remodeling, and reabsorption might lead to implant migration [11].

The quantity of migration has been mostly assessed through the maximal total point motion (MPTM). The MTPM is the unit of measure for the largest 3D migration of any point on the prosthesis surface [12]. The calculation of MTPM is mainly performed through Roentgen Stereophotogrammetric Analysis (RSA). There are two different methods: on the one hand, the manual marker-based; on the other hand, the semi-automatic CAD model-based [10]. Both methods are suitable for in vivo measurement of implant migration in clinical research studies concerning the TKR [13]. Indeed, RSA measurements are claimed to have a high prognostic precision in early detection of potential late occurring aseptic loosening $[14,15]$. Moreover, RSA allows the calculation of the "inter-marker distance" parameter, which can be seen as an index of material deformation within the different districts of a prosthetic implant (e.g., for the TKR, condyles and shield) [16]. RSA technique has been successfully used also in other joint surgery contexts and in presence alternative material solutions, e.g., in hip prosthesis to assess migration and material deformation of less stiff 


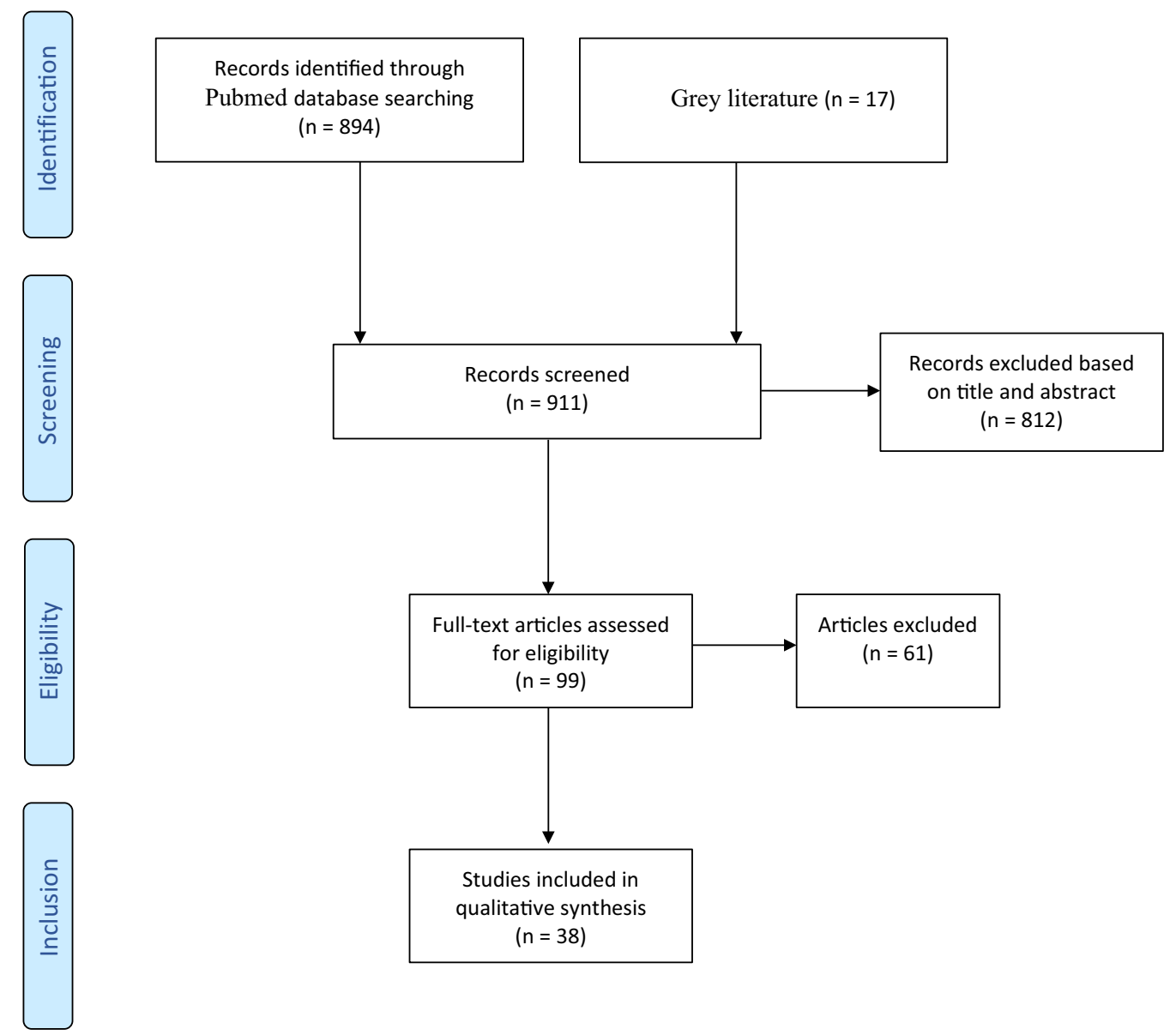

Figure 1. Flow chart of the narrative review according to the PRISMA guidelines

stems [17] and in spinal arthrodesis to predict lumbosacral stability of carbon fiber-reinforced cages [18].

Since the migration is linked to bone remodeling, measurement of bone density is crucial. Therefore, the use of dual-energy X-ray absorptiometry (DEXA), evaluating the bone density, could be a useful tool. Indeed, DEXA analysis could be used also in the assessment of bone remodeling of the femoral condyles after TKR [7]. Three studies show a dominating tendency toward decrease in tibia and femur bone mineral density (BMD) after the implantation of TKR [7-19]. However, BMD was shown to be an effective tool only in some specific loading conditions, as stated in a preclinical cadaveric study [20].

\section{Quantification of migration and patients' outcomes}

Due to the lack of studies regarding the femoral component, no migration thresholds suggesting short- and long-term survival of the femoral component prosthetic implants were retrieved.
Migration patterns must be evaluated through at least three-times assessments, one at baseline and two followups within the first 2 years. For the tibial component, the most frequently reported follow-up time for MTPM evaluation was 1 year [10]. Nevertheless, the literature reported other time intervals, as well: 6 weeks, 3 months, 6 months, 2 years, 5 years, and 10 years [10, 14].

Three RSA studies have shown that loosening can be concretely assessed in the early postoperative period [12-22]. Henricson et al.[11] reported a displacement of the femoral component MTPM of $0.10 \mathrm{~mm}$ per year for cemented implant and $0.09 \mathrm{~mm}$ per year for the cementless implant, throughout a 10-year follow-up evaluation. Few studies correlated the amount of migration with the patients' outcomes. Henricson et al.[11] suggested that an annual migration of $0.10 \mathrm{~mm}$ seems compatible with good long-term performance and good clinical and functional outcomes at 10-year follow-up [11]. Gao et al [14] found the same clinical and radiological results with patients younger than 60 years old.

These results are in accordance with Park et al.[23], who evaluated the clinical and radiological results comparing the identical cemented or cementless TKR design, implanted 


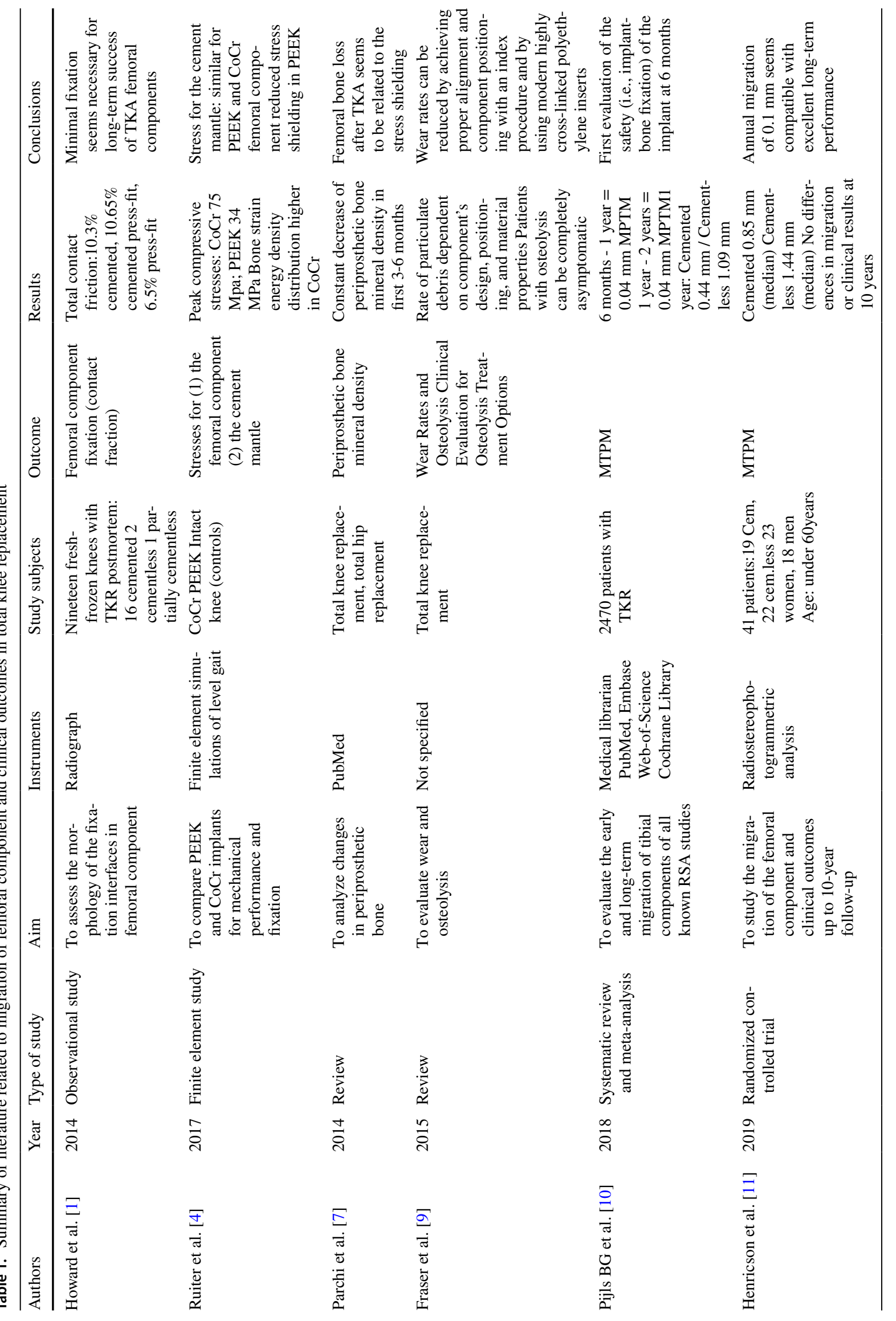




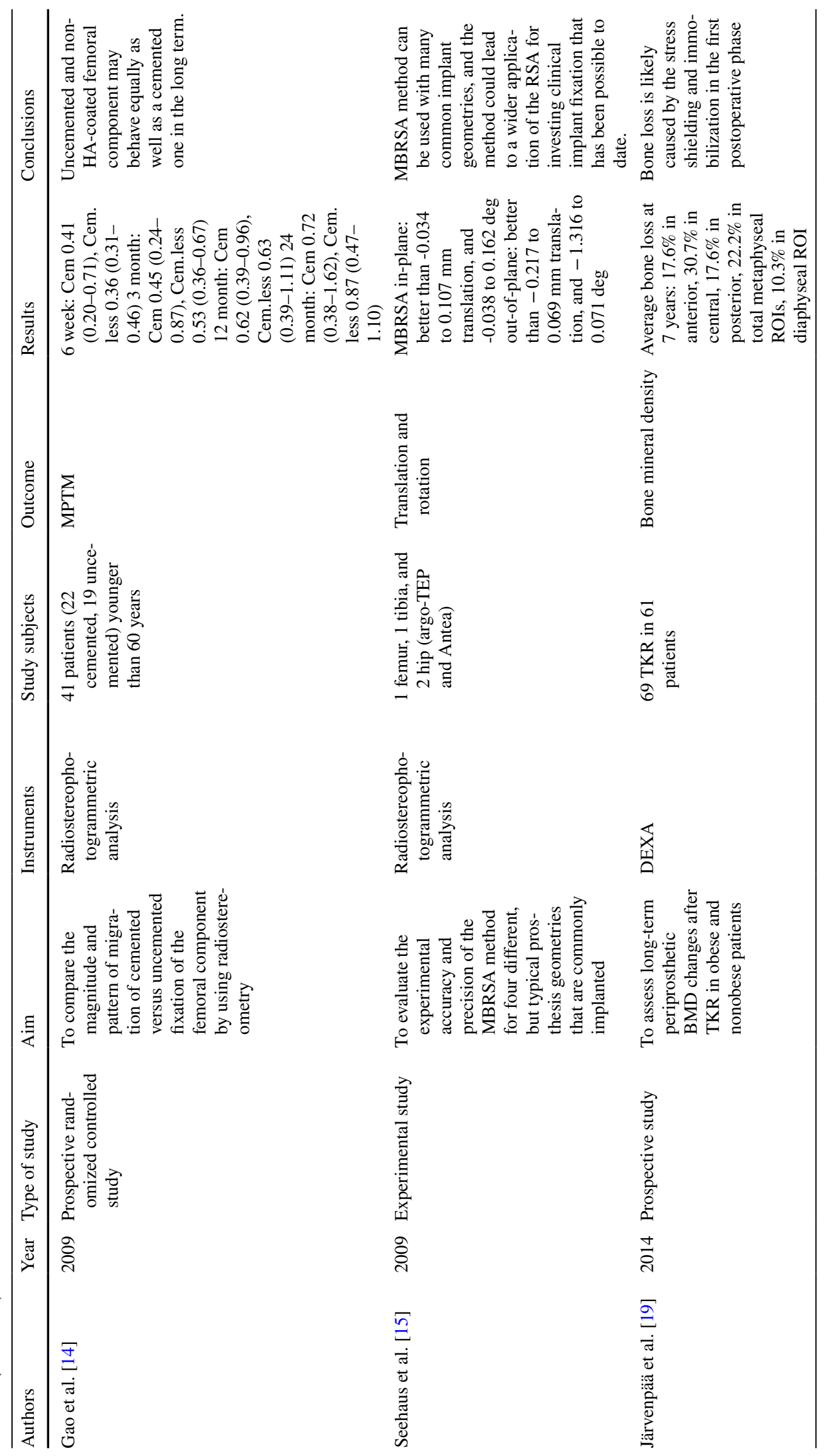




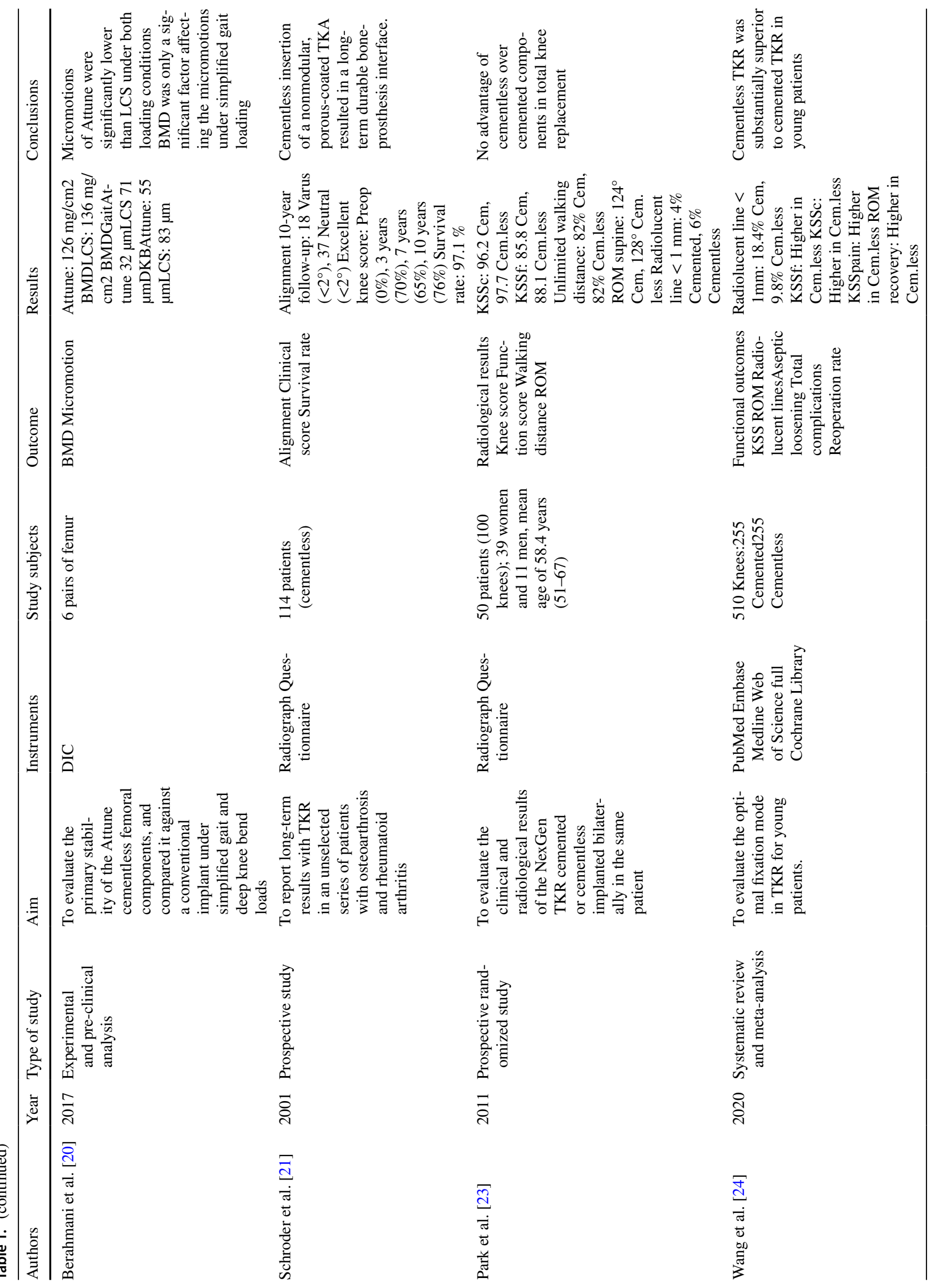



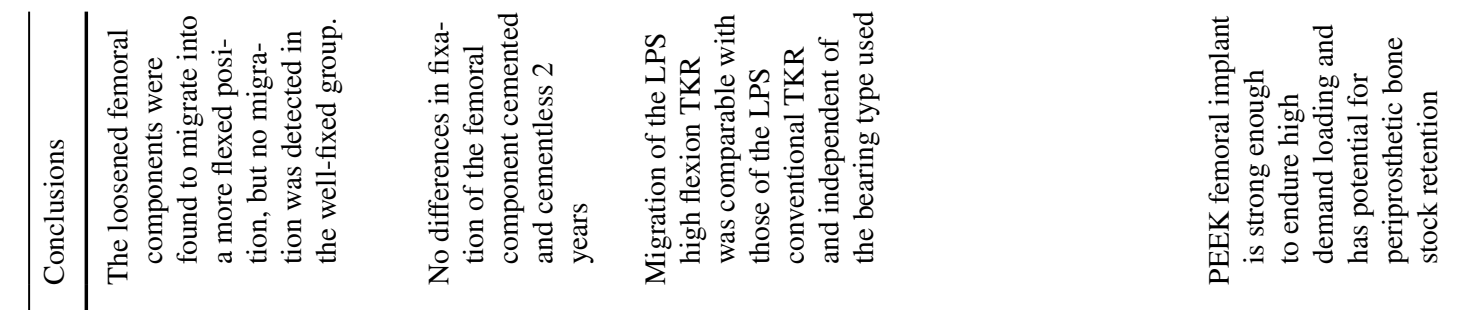

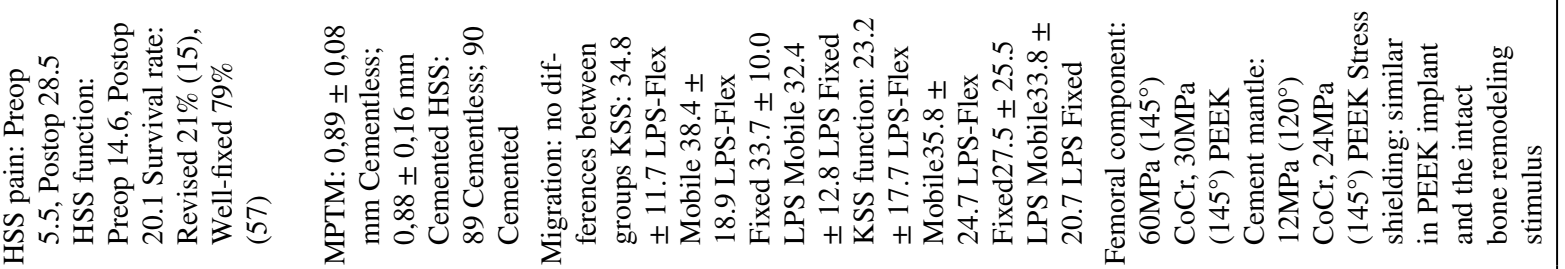

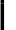

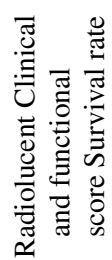
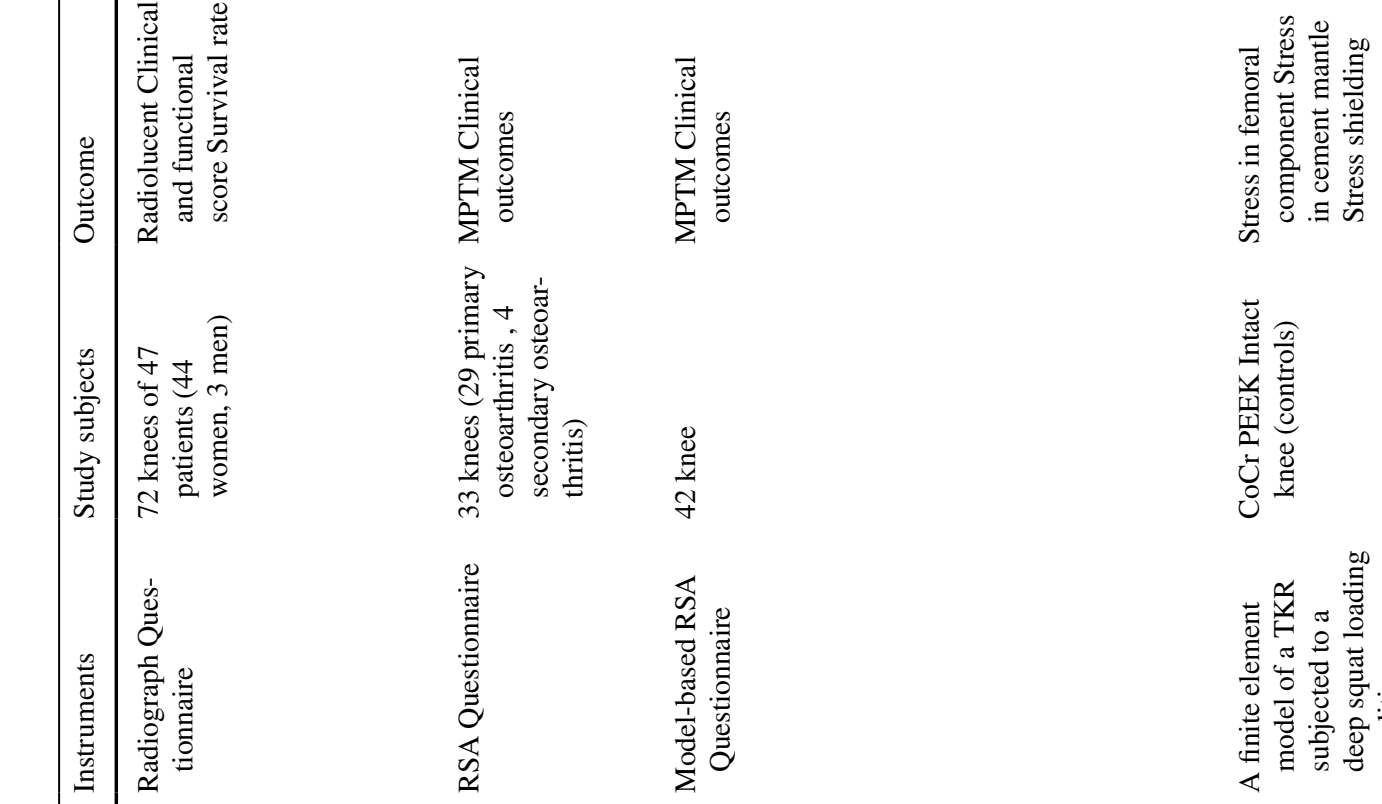

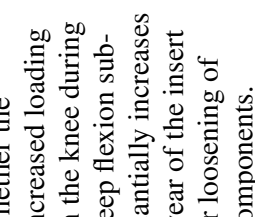

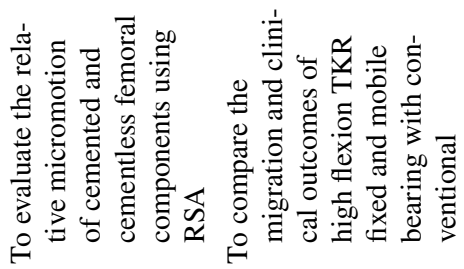

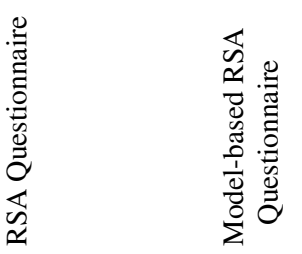

$\frac{\substack{2 \\ \frac{\pi}{7}}}{8}$

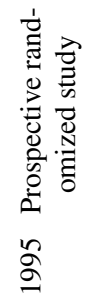

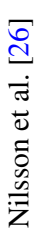
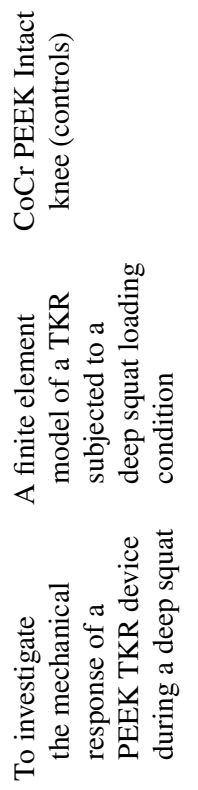

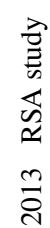

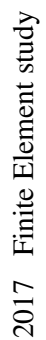

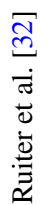

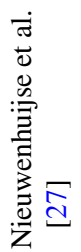




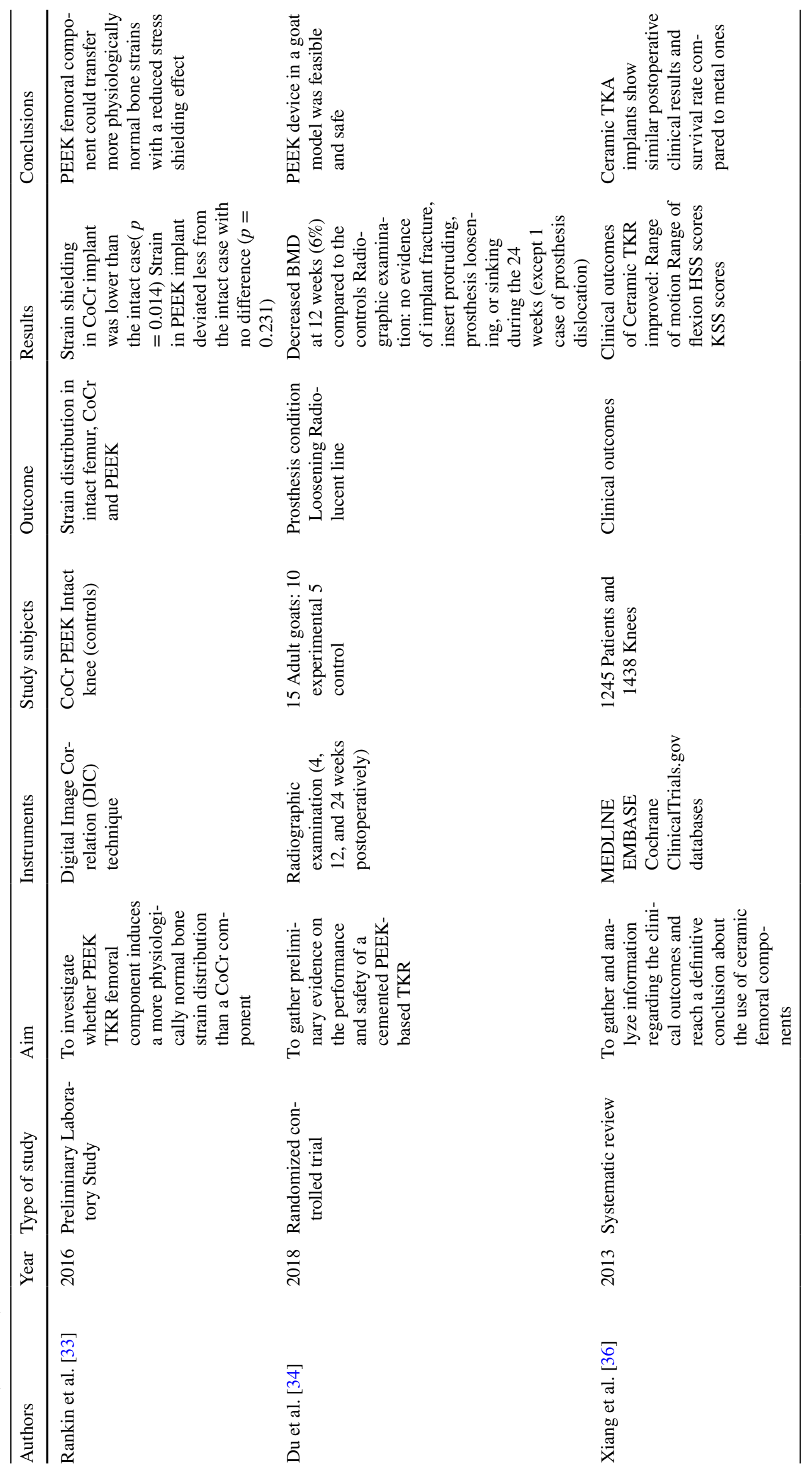




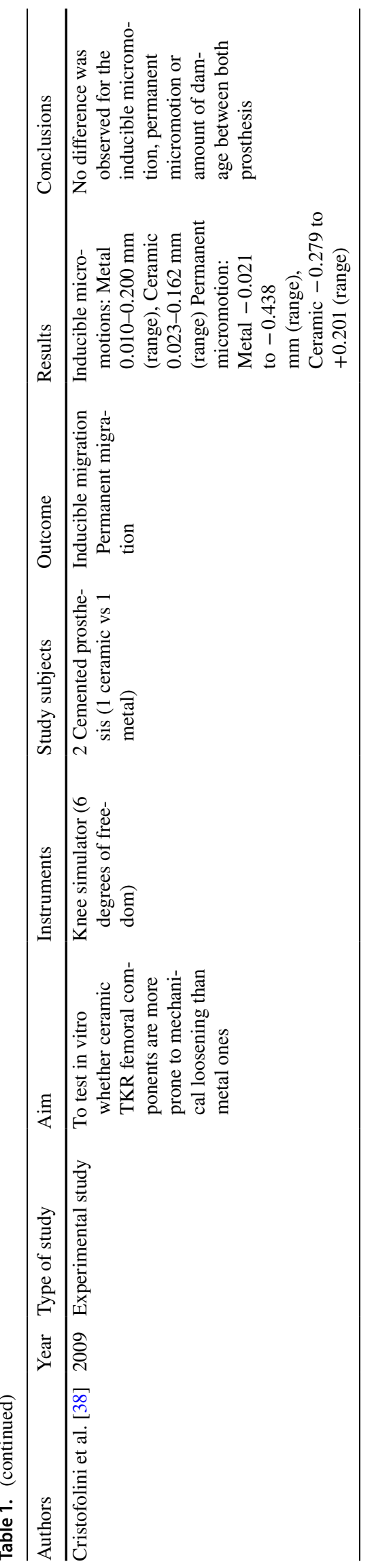

bilaterally in the same patient. They showed that after 14 years from surgery, the survival rate was $100 \%$ for both femoral components. Moreover, no differences were found in the outcomes like KSS, Western Ontario and McMaster Universities Arthritis Index (WOMAC), Visual Analogue Scale (VAS), range of movement (ROM), and radiological results.

On the contrary, Wang et al.[24] reported that the cementless group had better KSS-function and KSS-pain, better ROM recovery, and fewer radiolucent lines $(<1 \mathrm{~mm})$ than the cemented one, in a systematic review with $>500$ knees comparing postoperative outcomes of fixation in primary TKR for young patients ( $<65$ years). Hence, they suggested that cementless TKR was substantially superior to cemented TKR in young patients [24].

A further study showed that the migration strongly affects TKR outcomes: in revised TKR with high-flexion design, the loosened femoral components migrated into a position of increased flexion from a mean of $4^{\circ}$ immediately postoperatively to a mean of $7^{\circ}$ at the final review, whereas no migration into flexion was observed in the control TKR group [25].

Two more RSA studies compared different TKR designs at 2- [26] and 5-years [27] follow-up. The former did not find differences in MTPM between cemented $(0.88 \mathrm{~mm})$ and cementless $(0.89 \mathrm{~mm})$ TKR designs. For both groups, the MTPM was higher in the posterior condyles. Peculiarly, the only one case of revision was predicted by an MTPM up to $4.1 \mathrm{~mm}$ at 12 months. The authors further stated that such loosening could be caused by trabecular microfractures occurring some millimeters away from bone-implant interface, in presence of bone softened due to stress-shielding [27]. The latter study did not find differences between four TKR designs (high/conventional flexion with fixed/mobile bearing). The MTPM was always about $1 \mathrm{~mm}$. The only case of loosening presented with early migration over $2 \mathrm{~mm}$ within the first 3 months and reached up to $12 \mathrm{~mm}$ at one year.

\section{Alternative solutions to standard CoCr implants}

The vast majority of TKR implants found in the present review were made of $\mathrm{CoCr}$ alloy. As evidenced from the literature search, nonsignificant migration differences were found between different TKR designs. Therefore, implant loosening might be influenced by further factors, e.g., the material properties of the component. The two main alternatives found in the literature regarded the use of nonmetal materials, i.e., the polyethylene and the ceramic. The former was found either in terms of all-polyethylene or polyetheretherketone (PEEK). Polyethylene is less stiff than $\mathrm{CoCr}$ alloys and is therefore claimed to reduce the stress shielding at bone-implant interface [28] 
All polyethylene material was only used in tibial components in TKR, and the MPTM has been evaluated with respect to the metal-backed ones. The most recent studies [28-31] underlined a comparable amount of migration and risk of loosening between the two different materials. Furthermore, Norgren at al. [28] found a greater internal-external rotation in metal-backed tibial components and ascribed it to a greater stiffness of the latter.

Only few pre-clinical studies reported the use PEEK material in TKR context. Such material has already been used in different surgical scenarios, such as spinal and cranio-maxillofacial surgery, and it has shown a good level of rigidity, durability, and biocompatibility [4]. A finite element study analyzing the prosthetic implant loads during a gait cycle predicted that the performance of the PEEK femoral component would not be inferior to the $\mathrm{CoCr}$ femoral implant [4]. They also suggested that PEEK implant could cause a lower periprosthetic stress shielding compared to a standard implant [4].

The same type of analysis was performed during a high demanding activity (deep squat). PEEK implant showed higher compressive and lower tensile cement stress, thus demonstrating no increased risk of failure compared to the CoCr implant [32]. Furthermore, in the same study, the PEEK component showed bone strains more similar to the intact bone than the CoCr component [32].

Rankin et al.[33] used a digital image correlation (DIC) technique to evaluate bone strain distribution of the PEEK femoral component. Such prosthesis produced a bone surface strain field closer to that of the intact bone case. This further demonstrates that the reduced stiffness of PEEK implants compared with $\mathrm{CoCr}$ has the potential to reduce stress shielding and the risk of aseptic loosening, hence potentially improving long-term bone preservation [33].

This type of prosthesis has been tested on animal in vivo models, as well: Du et al. [34] demonstrated that cemented PEEK knee replacement devices in a goat model are feasible and safe, as on the basis of radiographic images, there was no evidence of implant fracture, insert protruding, prosthesis loosening, or sinking during the 24 weeks, except for one case of prosthesis dislocation, that did not affect its activity as soft tissue could maintain the stability of the joint. Moreover, the goats returned to perform activities like squatting, standing up, jumping, and running.

Although PEEK material for TKR demonstrated promising results in pre-clinical investigations, no studies have been carried out in vivo on human patients. Therefore, its dependability in a clinical context is yet to be confirmed. However, if roughly equating the two polyethylene materials (all polyethylene and PEEK), similar migration results could be argued in vivo for a femoral PEEK component.

Ceramic components are claimed for the higher biocompatibility, durability, and resistance to scratching with respect to $\mathrm{CoCr}$ alloy [35]. Indeed, ceramic prosthetic implant was used in the TKR procedure with excellent longterm joint function and survival [36]. A prospective study published in 2013 investigated the short-term outcomes of the ceramic femoral component TKR and found comparable results to the metal femoral TKR [37]. Furthermore, an in-vitro study published in 2008 by Cristofolini et al. [38] investigated migration of $\mathrm{CoCr}$ and ceramic femoral component under cycle loadings and concluded that no sign of loosening nor significant differences were present between the implants. Therefore, this study underlined that ceramic femoral component is not mechanically inferior to a standard CoCr. Nevertheless, no recent studies (less than 10 years) investigating migration on ceramic components were retrieved in the present review.

\section{Conclusion}

Only a limited number of studies evaluated micromotion of the TKR femoral component. There is no total agreement regarding the migration causes; at the same time, there are contrasting opinions about patients' clinical outcomes after surgery. At the present time, the RSA technique is the most commonly used, as well as the most accurate tool to evaluate migration. Indeed, it is recognized by the scientific literature as an instrument to predict the stability and the lifetime of the prosthetic implant, both for femoral and tibial components.

Furthermore, the study raised up possible alternative solutions, such as polyethylene and ceramics. Though the latter showed good long-term results, no recent studies were retrieved (less than 10 years). This aspect could be symptomatic of an obsolescence of such alternative. PEEK material seems a suitable solution because of reduced material stiffness, which may lead to a limited stress shielding [32]. However, further studies on patients are needed to evaluate the benefits and long-term survival of such alternative in a real clinical scenario.

Given the successful use of RSA for the assessment of migration and material deformation in presence of alternative materials in other body districts, such application could be extended to a TKR context as well.

Authors' contribution R.Z. contributed to the study design, conducted the articles search, contributed to results interpretation, drafted the manuscript, approved the final version. S.D.P. contributed to the study design, contributed to results interpretation, contributed to drafting the manuscript, approved the final version. G.A. conducted the articles search, contributed to results interpretation, approved the final version. D.A. contributed to the study design, contributed to results interpretation, contributed to drafting the manuscript, approved the final version. S.Z. had the main role in conceiving and designing the study, 
contributed to results interpretation, supervised the entire workflow, approved the final version. G.B. contributed to the study design, contributed to article search, contributed to results interpretation, approved the final version. L.B. had the main role in conceiving and designing the study, contributed to results interpretation, supervised the entire workflow, approved the final version.

Funding Open access funding provided by Alma Mater Studiorum Università di Bologna within the CRUI-CARE Agreement. A commer-

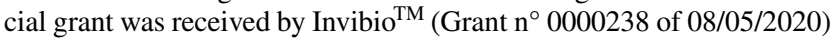
to support the present research study.

\section{Compliance with ethical standards}

Conflict of interest The authors have no relevant financial or non-financial interests to disclose.

Availability of the data and material The authors confirm that the data supporting the findings of this study are available within the article.

Open Access This article is licensed under a Creative Commons Attribution 4.0 International License, which permits use, sharing, adaptation, distribution and reproduction in any medium or format, as long as you give appropriate credit to the original author(s) and the source, provide a link to the Creative Commons licence, and indicate if changes were made. The images or other third party material in this article are included in the article's Creative Commons licence, unless indicated otherwise in a credit line to the material. If material is not included in the article's Creative Commons licence and your intended use is not permitted by statutory regulation or exceeds the permitted use, you will need to obtain permission directly from the copyright holder. To view a copy of this licence, visit http://creativecommons.org/licenses/by/4.0/.

\section{References}

1. Howard KI, Miller MA, Damron TA, Mann KA (2014) The distribution of implant fixation for femoral components of TKA: a postmortem retrieval study. J Arthroplast 29(9):1863-1870. https ://doi.org/10.1016/j.arth.2014.04.014

2. Evans JT, Walker RW, Evans JP, Blom AW, Sayers A, Whitehouse MR (2019) How long does a knee replacement last? A systematic review and meta-analysis of case series and national registry reports with more than 15 years of follow-up. Lancet 393(10172):655-663. https://doi.org/10.1016/s0140 $-6736(18) 32531-5$

3. Sadoghi P, Liebensteiner M, Agreiter M, Leithner A, Böhler N, Labek G (2013) Revision surgery after total joint arthroplasty: a complication-based analysis using worldwide arthroplasty registers. J Arthroplast 28(8):1329-1332. https://doi.org/10.1016/j. arth.2013.01.012

4. de Ruiter L, Janssen D, Briscoe A, Verdonschot N (2017) A preclinical numerical assessment of a polyetheretherketone femoral component in total knee arthroplasty during gait. J Exp Orthop. https://doi.org/10.1186/s40634-017-0078-4

5. Kasahara Y, Majima T, Kimura S, Nishiike O, Uchida J (2013) What are the causes of revision total knee arthroplasty in Japan? Knee. Clin Orthop Relat Res 471(5):1533-1538. https://doi. org/10.1007/s11999-013-2820-2

6. Schroer WC, Berend KR, Lombardi AV, Barnes CL, Bolognesi MP, Berend ME, Nunley RM (2013) Why are total knees failing today? Etiology of total knee revision in 2010 and 2011. J
Arthroplast 28(8 SUPPL):116-119. https://doi.org/10.1016/j. arth.2013.04.056

7. Parchi PD, Cervi V, Piolanti N, Ciapini G, Andreani L, Castellini I, Lisanti M (2014) Densitometric evaluation of periprosthetic bone remodeling. Clin Cases Miner Bone Metab 11(3):226-231

8. Lavernia CJ, Rodriguez JA, Iacobelli DA, Hungerford DS, Krackow KA (2014) Bone mineral density of the femur in autopsy retrieved total knee arthroplasties. J Arthroplast 29(8):1681-1686. https://doi.org/10.1016/j.arth.2014.03.010

9. Fraser JF, Werner S, Jacofsky DJ (2015) Wear and loosening in total knee arthroplasty: a quick review. J knee surg 28(2):139-144. https://doi.org/10.1055/s-0034-1398375

10. Pijls BG, Plevier JWM, Nelissen RGHH (2018) RSA migration of total knee replacements: a systematic review and meta-analysis. Acta Orthop 89(3):320-328. https://doi.org/10.1080/17453 674.2018.1443635

11. Henricson A, Wojtowicz R, Nilsson KG, Crnalic S (2019) Uncemented or cemented femoral components work equally well in total knee arthroplasty. Knee Surg, Sp Traumatol, Arthrosc 27(4):1251-1258. https://doi.org/10.1007/s00167-018-5227-5

12. Ryd L, Albrektsson BE, Carlsson L, Dansgard F, Herberts P, Lindstrand A, S, T.-L. (1995) Roentgen stereophotogrammetric analysis as a predictor of mechanical loosening of knee prostheses. J Bone Jt Surg Br 77(3):377-83

13. IJsseldijk EA, Valstar ER, Stoel BC, Nelissen RGHH, Reiber JHC, Kaptein BL (2011) The robustness and accuracy of in vivo linear wear measurements for knee prostheses based on model-based RSA. Journal of Biomechanics https://doi.org/10.1016/j.jbiom ech.2011.08.013

14. Gao F, Henricson A, Nilsson KG (2009) Cemented versus uncemented fixation of the femoral component of the NexGen CR total knee replacement in patients younger than 60 years. A Prospective Randomised Controlled RSA Study. Knee 16(3):200-206

15. Seehaus F, Emmerich J, Kaptein BL, Windhagen H, Hurschler C (2009) Experimental analysis of model-based roentgen stereophotogrammetric analysis (MBRSA) on four typical prosthesis components. J Biomech Eng 131(4):1-10. https://doi. org/10.1115/1.3072892

16. Russo A, Bragonzoni L, Trozzi C, Iacono F, Visani A, Marcacci M (2008) Radiostereometric measurement of polyethylene deformation pattern in meniscal bearing TKR at 5 years follow-up. Knee Surg, Sp Traumatol, Arthrosc 16(2):142-147. https://doi. org/10.1007/s00167-007-0429-2

17. Kärrholm J, Anderberg C, Snorrason F, Thanner J, Langeland N, Malchau H, Herberts P (2002) Evaluation of a femoral stem with reduced stiffness. J Bone Jt Surg-Am 84(9):1651-1658. https:// doi.org/10.2106/00004623-200209000-00020

18. Pape D, Fritsch E, Kelm J, Müller K, Georg T, Kohn D, Adam F (2002) Lumbosacral stability of consolidated anteroposterior fusion after instrumentation removal determined by roentgen stereophotogrammetric analysis and direct surgical exploration. Spine 27(3):269-274. https://doi.org/10.1097/00007632-20020 2010-00014

19. Järvenpää J, Soininvaara T, Kettunen J, Miettinen H, Kröger H (2014) Changes in bone mineral density of the distal femur after total knee arthroplasty: a 7-year DEXA follow-up comparing results between obese and nonobese patients. Knee 21(1):232235. https://doi.org/10.1016/j.knee.2013.03.004

20. Berahmani S, Hendriks M, Wolfson D, Wright A, Janssen D, Verdonschot N (2017) Experimental pre-clinical assessment of the primary stability of two cementless femoral knee components. J Mech Behav Biomed Mater 75(July):322-329. https://doi. org/10.1016/j.jmbbm.2017.07.043

21. Schrøder HM, Berthelsen A, Hassani G, Hansen EB, Solgaard S (2001) Cementless porous-coated total knee arthroplasty: 10-Year 
results in a consecutive series. J Arthroplast 16(5):559-567. https ://doi.org/10.1054/arth.2001.23565

22. Toksvig-Larsen S, Ryd L, Lindstrand A (1998) Early inducible displacement of tibial components in total knee prostheses inserted with and without cement: a randomized study with roentgen stereophotogrammetric analysis. J Bone Jt surg Am vol, 80(1), 83-9. Retrieved from http://www.ncbi.nlm.nih.gov/pubme d/9469313

23. Park JW, Kim YH (2011) Simultaneous cemented and cementless total knee replacement in the same patients: A prospective comparison of long-term outcomes using an identical design of NexGen prosthesis. J Bone Jt Surg. https://doi.org/10.1302/0301620X.93B11.27507

24. Wang K, Sun H, Zhang K, Li S, Wu G, Zhou J, Sun X (2020) Better outcomes are associated with cementless fixation in primary total knee arthroplasty in young patients. Medicine 99(3):e18750. https://doi.org/10.1097/md.0000000000018750

25. Han HS, Kang SB, Yoon KS (2007) High incidence of loosening of the femoral component in legacy posterior stabilisedflex total knee replacement. J Bone Jt Surg Br. https://doi. org/10.1302/0301-620X.89B11.19840

26. Nilsson KG, Kärrholm J, Linder L (1995) Femoral component migration in total knee arthroplasty: randomized study comparing cemented and uncemented fixation of the Miller-Galante I design. J Orthop Res 13(3):347-356. https://doi.org/10.1002/jor.11001 30308

27. Nieuwenhuijse MJ, Van Der Voort P, Kaptein BL, Van Der Linden HMJ, Valstar ER, Nelissen RGHH (2013) Fixation of high-flexion total knee prostheses: five-year follow-up results of a four-arm randomized controlled clinical and roentgen stereophotogrammetric analysis study. J Bone Jt Surg - Series A 95(19):1-11. https:// doi.org/10.2106/JBJS.L.01523

28. Norgren B, Dalén T, Nilsson K (2004) All-poly tibial component better than metal-backed: a randomized RSA study. Knee 11(3):189-196. https://doi.org/10.1016/S0968-0160(03)00071-1

29. Longo UG, Ciuffreda M, D’Andrea V, Mannering N, Locher J, Denaro V (2017) All-polyethylene versus metal-backed tibial component in total knee arthroplasty. Knee Surg, Sp Traumatol, Arthrosc 25(11):3620-3636. https://doi.org/10.1007/s0016 7-016-4168-0

30. Hasan S, Marang-Van De Mheen PJ, Kaptein BL, Nelissen RGHH, Toksvig-Larsen S (2019) All-polyethylene versus metal-backed posterior stabilized total knee arthroplasty: similar 2-year results of a randomized radiostereometric analysis study. Acta Orthop 90(6):590-595. https://doi.org/10.1080/17453674.2019.1668602

31. Van Hamersveld KT, Marang-Van De Mheen PJ, Nelissen RGHH, Toksvig-Larsen S (2018) Migration of all-polyethylene compared with metal-backed tibial components in cemented total knee arthroplasty: a randomized controlled trial. Acta Orthop 89(4):412-417. https://doi.org/10.1080/17453674.2018.1464317

32. de Ruiter L, Janssen D, Briscoe A, Verdonschot N (2017) The mechanical response of a polyetheretherketone femoral knee implant under a deep squatting loading condition. Proc Ins Mech Eng, Part H: J Eng Med 231(12):1204-1212. https://doi. org/10.1177/0954411917738805

33. Rankin KE, Dickinson AS, Briscoe A, Browne M (2016) Does a PEEK femoral TKA implant preserve intact femoral surface strains compared with CoCr? A preliminary laboratory study. Clin Orthop Relat Res. https://doi.org/10.1007/s11999-016-4801-8

34. Du Z, Zhu Z, Yue B, Li Z, Wang Y (2018) Feasibility and safety of a cemented PEEK-on-PE knee replacement in a goat model: a preliminary study. Artif Org 42(8):E204-E214. https://doi. org/10.1111/aor.13101

35. Solarino G, Piconi C, De Santis V, Piazzolla A, Moretti B (2017) Ceramic total knee arthroplasty: Ready to go? Joints 5(4):224228. https://doi.org/10.1055/s-0037-1607428

36. Xiang S, Zhao Y, Li Z, Feng B, Weng X (2019) Clinical outcomes of ceramic femoral prosthesis in total knee arthroplasty: a systematic review. J Orthop Surg Res 14(1):1-10. https://doi. org/10.1186/s13018-019-1090-4

37. Bergschmidt P, Bader R, Kluess D, Zietz C, Schwemmer B, Kundt G, Mittelmeier W (2013) Total knee replacement system with a ceramic femoral component versus two traditional metallic designs: a prospective short-term study. J Orthop Surg (Hong Kong) 21(3):294-299. https://doi.org/10.1177/230949901302100 306

38. Cristofolini L, Affatato S, Erani P, Tigani D, Viceconti M (2009) Implant fixation in knee replacement: preliminary in vitro comparison of ceramic and metal cemented femoral components. Knee 16(2):101-108. https://doi.org/10.1016/j.knee.2008.08.006

Publisher's Note Springer Nature remains neutral with regard to jurisdictional claims in published maps and institutional affiliations. 